\title{
The ACRL/Harvard Leadership Institute
}

\author{
Highlights from the third annual institute
}

by Linda Marie Golian and Rebecca Donlan

"The instruction was excellent; it surpassed my expectations. The differences in approacb and wealth of experience and candor of the instructors were wonderful."

"I feel I got what I wanted in terms of learning more about leadersbip-wbat it means and bow to be a better leader."

"I appreciated learning about the chatlenges of institutions which are quite different from mine."

"I will be recommending otbers from $m y$ institution and hope that they bave as positive experience as I bave had. I will use the material I am taking bome."

These are just a few of the overwhelmingly positive comments from librarians who participated in the 2001 ACRL/Harvard Leadership Institute, as reported in the official institute evaluation summary. This year's institute was held at Harvard University in Cambridge, Massachusetts, from August 19-24, 2001.

Building upon a foundation of two successful years of outstanding instructors, a solid curriculum, and sound educational practices, the third annual institute once again garnered winning reviews and the highest praise from graduating participants.

Co-sponsored by ACRL and the Harvard Institutes for Higher Education, the institute is an intensive residential experience for librarians who fill leadership roles in their institutions. The 63 members of the Class of 2001 have many different positions, including (but not limited to) library director, associate or assistant library director, department head, and team leader.

Participants came from many different kinds of academic institutions-those with large and small student populations equally represented. From community colleges to ARL members, from private and state funded institutions, the participants in the Class of 2001 represented all types of college and research libraries.

In the official evaluation summary of this year's institute, faculty earned high praise from the participants for the quality of their teaching, their boundless energy, their obvious love of teaching, and their interest in and respect for our work. Many of us were surprised to learn about the intense schedules our instructors maintain over the summer months to provide similar training to professionals in other

\section{About the authors}

Linda Marie Golian is the reference team leader and education librarian at Florida Gulf Coast University Library, e-mail: Igolian@fgcu.edu; Rebecca Donlan is the technical senvices and Web development team leader at Florida Gulf Coast University Library, e-mail:rdonlan@fgcu.edu 
fields. The five instructors were always prepared and willing to go the extra mile to make our learning experience outstanding and memorable.

Cliff Baden, educational chair of the leadership institute and director of programs in professional education at the Harvard Graduate School of Education, had the critical task of setting the tone for the institute at the opening session late on Sunday afternoon. He gracefully set the stage by inviting participants to reflect upon two issues during the course of the institute: How well positioned is my organization to meet current and future challenges? How effective is my own leadership?

Joan V. Gallos, professor of higher education and former dean of the School of Education at the University of Missouri-Kansas City, led most of the discussion concerning Reframing Organizations, ${ }^{1}$ which was used as the textbook for the institute. With this text, Gallos helped us understand how to make sense of organizational dynamics and lead organizational change by "reframing" our perceptions of the organizations in which we work.

James P. Honan, lecturer on education at the Harvard Graduate School of Education and co-chair of the Institute of Educational Management, used the case study method to explore the many ways that planning is used in colleges and universities to align institutional vision and mission, priorities, and resources.

Robert Kegan is a lifespan development psychologist and educational chair of the Institute for Management and Leadership in Education. Based upon the research published in his book How the Way We Talk Can Change the Way We Work' (co-authored with Lisa Lahey), Kegan introduced the participants to the language of transformation and its use as an agent for organizational growth and development.

Maureen Sullivan, an organizational development consultant and past-president of ACRL and LAMA, focused upon the practical library-related applications of the case stuclies examined in Honan's sessions.

Each instructor brought unique knowledge and a spirit of transformation to the institute. While their styles varied, the instructors' dedication and effectiveness were equally strong.
They worked as a unified instructional team, building on each other's sessions.

\section{Curriculum}

Librarians seldom think about the challenges faced by leaders of other types of institutions. The institute is designed to help participants strengthen their roles as library leaders by learning from case studies that illustrate the challenges of leadership in academic and business organizations.

The curriculum for the institute was a series of interactive learning activities, including lectures, case studies, discussion groups, and social activities. The curriculum centered on topics of reframing leadership, diagnosing organizations, leading and planning organizations in a changing context, learning the language of transformation, and considering the implications of the lessons learned for our own leadership practice. Participants felt that "the program had a great balance of theory and practice."

The term "lecture" may be a bit misleading. The faculty of the 2001 institute did not stand in front of the room and recite canned speeches filled with facts and figures. In fact, the lecture style of all the instructors was quite interactive and engaging, leading to effective large group discussion and interaction.

Gallos introduced the four frames of reference (structural, human resources, political, and symbolic) drawn from Reframing Organizations. Participants learned how to view leadership through four distinctly different perspectives and were asked to evaluate their individual strengths and weaknesses in each of the four frames.

Building upon the four frames, Honan used the case study method to help the participants practice using the new four-framework tool. In three quick-paced sessions, Honan led an analysis of three real-life case studies that are still evolving today. Interestingly, none of these cases dealt with library management. In one of these sessions, Sullivan expanded on the SUNY-Farmingdale case and linked it to library implications and strategies.

The institute also provided opportunities for small-group discussion. Mornings began with an hour-long discussion group. Groups discussed daily reading assignments, shared personal mission statements, and discussed 
specific management situations. In our groups, we shared and discussed real situations from our organizations. These small discussion groups allowed participants to share experiences in a more intimate setting, with people who were genuinely interested, respectful, and helpful. Ninety percent of the participants reported that their small discussion group was a highlight of their institute experience; many plan to stay in contact with each other through phone calls or e-mail.

Although classes entailed nightly extensive readings, there was ample time for social and informal interaction. Almost all participants said they found the daily schedule and the general pace of the institute appropriate. Participants commented that they appreciated the time built into the schedule for talking with other participants. One participant stated, "I liked having a few days with nothing planned after 3:30 as it gave me a chance to refuel and reflect."

The planned social activities included an opening reception at the Radcliffe Sunken Gardens, a tour of the Harvard Campus, a reception at the Harvard Faculty Club, a New England Clambake with fresh lobster, and a closing champagne and strawberry toast. Arrangements were made for interested participants to visit the Widener Library, the Gutman Library, and the Harvard Museum of Natural History.

We learned a lot and we worked hard, but we also had fun and fostered new relationships.

\section{Pilot project}

Robert Kegan provided a unique opportunity by inviting participants to join a special pilot project. During class sessions, each of us worked with a partner to discuss various aspects of transformative language, as outlined in How the Way We Talk Can Change the Way We Work. For the pilot project, Kegan and co-author Lisa Lahey will select four or five sets of partners, who will apply face-to-face communication techniques to other (primarily electronic) modes of communication.

\section{Applying what we learned}

How well the participants of the 2001 institute apply what they have learned has yet to be discovered. Many participants commented that they had experienced a shift of perspec-

\section{Ninety percent of the participants reported that their small discussion group was a highlight of their institute experience. . . .}

tive on their problems and their decisionmaking processes. For example, many participants commented that in the future, they would view organizational opportunities and situations through all four frameworks for more effective decision-making. Others said they would seek multiple perspectives in building consensus through "the language of public agreement."

The institute also provided an opportunity for critical reflection. We learned that changing one's leadership style is possible, but it is hard work, requiring persistence and diligence. We learned, too, that leading an academic library entails more than understanding our staff or patron perspectives.

According to a fellow attendee, since attending the institute, "I do feel that I have been more reflective in my work and more mindful of the big picture things that we discussed." Knowing the "big picture" of our educational organizations is a critical aspect of academic library leadership, allowing us to work "smarter, not harder" to attain our vision. It will be interesting to note, over the next few years, how many participants move into different leadership roles in their current or new academic institutions.

\section{Recommendations to the Class of 2002}

The outstanding reviews and praise from past participants are strong support for ACRL's continued support of the Harvard Leadership Institute. Currently, there are very few professional development opportunities for midand upper-level academic librarians. We sincerely hope that ACRL will continue to provide this educational service to the academic library community by making a long-term commitment to sponsoring annual classes beyond 2002

In anticipation of this welcome opportunity, librarians participating in future institutes should consider the following sage advice from those in the three previous classes: 
1) Talk with past participants about their experiences. Although everyone's experience is different, talking with previous participants can better prepare future attendees for this intense experience. Hearing how the curriculum, schedule, case studies, and social events work together for a holistic learning experience that is manageable and fun is reassuring and comforting for the busy professional who has not participated in a formal educational experience for several years.

2) Visit the Web site and meet your group ahead of time. Prior to the institute, you are given a Web site for your specific class, which includes information about the instructors, curriculum, case studies, participants, discussion groups, and information about Harvard and the Harvard area Besides providing a wealth of local information (bookstores, restaurants, library hours, etc.), the Web site also introduces you to the discussion group to which you have been assigned. Consider e-mailing your group members prior to the institute. They are an incredibly rich source of information. For example, in one discussion group, one member was considering checking out laptops for a wireless LAN and it turned out that three other discussion group members were conducting pilot projects for this very same service.

3) Read Reframing Organizations by Bolman and Deal in its entirety. By the end of the week you will have been responsible for reading the entire book anyway. If you read it before attending the institute, you will have a better concept of how all the frameworks complement each other. Then, as readings are assigned each night, you can spend time reviewing the required chapters, and you will be able to spend more time reading and discussing the case studies.

4) If Robert Kegan is scheduled to be a 2002 institute instructor, consider purchasing How the Way We Talk Can Change the Way We Work. Although Kegan leads participants through a sample exercise drawn from the text during the Institute, having the book as a reference while the exercise is progressing and after the Institute is extremely beneficial.

5) One of the assignments this year was to write our "Leadership Autobiography." How did we get where we are today? We urge you to consider writing this before you attend, because it will help clarify your goals and concerns.
6) Clear the decks at home and at work. The participants who get the most out of the institute have taken steps to devote uninterrupted time to the very serious work of professional development and critical reflection. This is your special time to focus upon your leadership skills. As one of our classmates put it, "Part of the genius of the institute is that it provides a context for thought and reflection that we often don't enjoy in our daily work environment." Don't rob yourself of this opportunity by bringing along work.

7) Consider starting a learning journal. Change requires outward action and inward reflection, so taking the opportunity to capture your thoughts about the process in writing can be very fruitful.

8) Spend time on your personal case study. In past classes, participants were asked to prepare and submit a real-life case study before attending the institute. During the small discussion group periods, everyone has an opportunity to discuss their case study. Participants who spent considerable time developing their cases were rewarded with helpful insights, perspectives, and possible solutions.

9) Plan on working hard, but also plan on having fun and making new professional contacts that will last a lifetime. ACcording to one participant, "Since we spent a week together, I feel that I could contact many of these people to serve as a sounding board for future issues."

The institute is a once-in-a-lifetime opportunity for mid- and upper-level management academic librarians. The third annual ACRL/ Harvard Leadership Institute continued the pattern of providing an exceptional professional development experience, described by one participant as "something unique, but yet not in dreamland." We urge you to attend.

The authors would like to thank Clem Guthro, team leader for collection management at Macalester College, and Barbara Simpson Darden, director of library services at Kean University for their input.

\section{Notes}

1. Lee G. Bolman and Terrence E. Deal, Reframing Organizations (Jossey-Bass, 1997).

2. Robert Kegan and Lisa Laskow Lahey, How the Way We Talk Can Change the Way We Work (Jossey-Bass, 2001). 

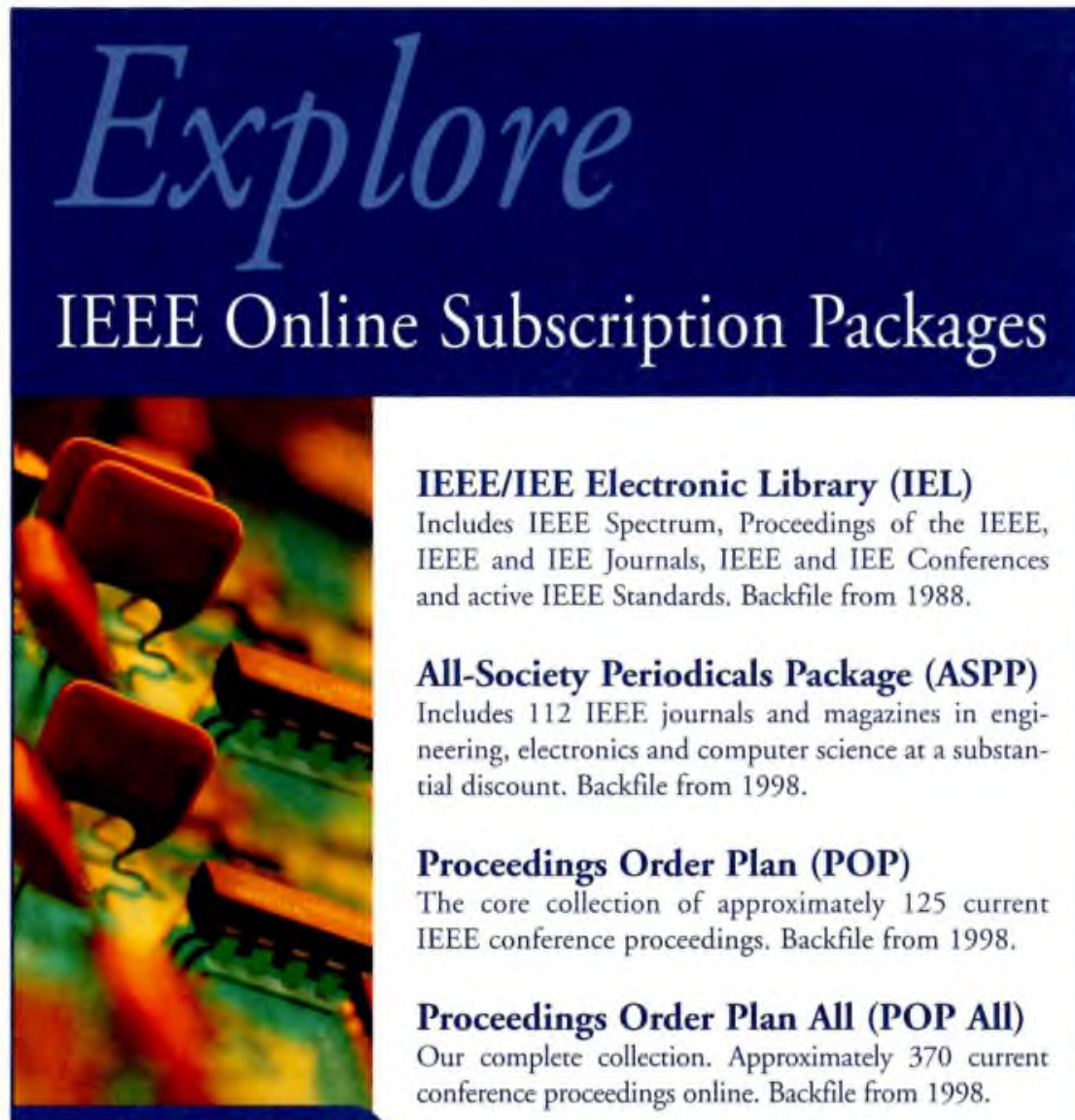

\section{IEEE/IEE Electronic Library (IEL)}

Includes IEEE Spectrum, Proceedings of the IEEE, IEEE and IEE Journals, IEEE and IEE Conferences and active IEEE Standards. Backfile from 1988.

\section{All-Society Periodicals Package (ASPP)}

Includes 112 IEEE journals and magazines in engineering, electronics and computer science at a substantial discount. Backfile from 1998.

\section{Proceedings Order Plan (POP)}

The core collection of approximately 125 current IEEE conference proceedings. Backfile from 1998.

\section{Proceedings Order Plan All (POP All)}

Our complete collection. Approximately 370 current conference proceedings online. Backfile from 1998.

For additional information or to arrange a free demonstration:

onlineproducts@ieee.org (email)

$+17329810060$ (phone)

\section{$+17329819667$} (fax)

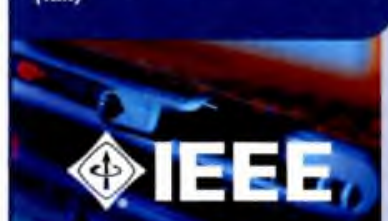

\begin{tabular}{l} 
IEEE ONLINE SUBSCRIPTION PACKAGES \\
INCLUDE \\
Weekly Content Updates \\
\hline Searchable INSPEC Abstract/Citation Records \\
\hline IHS Tech Support \\
\hline Browseable Tables of Contents \\
\hline Top Cited Journals in Electrical Engineering, \\
Telecommunications, and Computer Science* \\
\hline Interactive Reference Linking to Journal Articles \\
\hline - baind on IS/F ammual Journal Cination Report - 1999
\end{tabular}

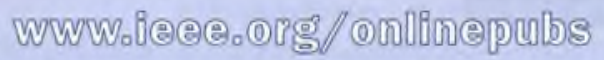

